\title{
Percepção dos alunos de um curso técnico integrado em automação industrial sobre a
}

$$
\text { utilização do eduScrum }
$$

Perception of students of an integrated technical course in industrial automation on the use of eduScrum

Percepción de los alumnos de un Curso Técnico Integrado en Automatización Industrial sobre el uso de eduScrum

Recebido: 04/05/2020 | Revisado: 06/05/2020 | Aceito: 13/05/2020 | Publicado: 23/05/2020

Norimar de Melo Verticchio

ORCID: http://orcid.org/0000-0001-8925-7264 Instituto Federal de Minas Gerais, Brasil E-mail: norimar.verticchio@ifmg.edu.br

Gabriel de Oliveira Soares

ORCID: http://orcid.org/0000-0001-8734-6415

Universidade Franciscana, Brasil

E-mail: gsoares8@outlook.com

\section{Resumo}

Este trabalho tem como objetivo analisar a percepção de alunos do $2^{\circ}$ ano do curso Técnico Integrado de Automação Industrial do IFMG campus Betim com relação à utilização do eduScrum como metodologia de ensino. O eduScrum é a aplicação na educação do framework Scrum. No eduScrum o professor apresenta aos alunos o porque estudar e o que será estudado e entregue, os alunos decidirão como vão aprender e desenvolver a atividade proposta. Essa metodologia possui várias etapas, tais como: Formação das equipes, Planejamento do Sprint, Desenvolvimento do Sprint, Reuniões Stand up, Revisão do Sprint e Retrospectiva do Sprint. Todas essas etapas são fundamentadas nos princípios da transparência, adaptação e inspeção. Esse estudo foi desenvolvido a partir de uma intervenção pedagógica, e para etapa da investigação das percepções, fez-se uso de uma pesquisa de campo. O eduScrum foi utilizado durante o primeiro trimestre de 2018 na disciplina de Manufatura Industrial, CNC e Sistemas Hidropneumáticos. Após o término do trimestre os 43 alunos responderam a um questionário no Google Forms. A utilização dessa metodologia foi 
muito satisfatória, sendo que $90,7 \%$ dos alunos gostariam que ela fosse utilizada no próximo trimestre. Os principais pontos favoráveis à utilização do eduScrum apresentado pelos alunos foram: o favorecimento da aprendizagem, o desenvolvimento do trabalho em grupo, da responsabilidade e autonomia.

Palavras-chave: eduScrum; Educação profissional; Competências transversais; Percepção.

\begin{abstract}
This work aims to analyze the perception of 2 nd year students of the Integrated Technician of Industrial Automation course at the IFMG campus Betim in relation to the use of eduScrum as a teaching methodology. EduScrum is the application in education of the Scrum framework. At eduScrum, the teacher presents students with why to study and what will be studied and delivered, students will decide how they will learn and develop the proposed activity. This methodology has several stages, such as: Team building, Sprint planning, Sprint development, Stand up meetings, Sprint review and Sprint retrospective. All of these steps are based on the principles of transparency, adaptation and inspection. This study was developed from a pedagogical intervention, and for the stage of investigating perceptions, field research was used. EduScrum was used during the first quarter of 2018 in the discipline of Industrial Manufacturing, CNC and Hydropneumatic Systems. After the end of the quarter, the 43 students answered a questionnaire on Google Forms. The use of this methodology was very satisfactory, and $90.7 \%$ of students would like it to be used in the next quarter. The main points favorable to the use of eduScrum presented by the students were: the favor of learning, the development of group work, responsibility and autonomy.
\end{abstract}

Keywords: eduScrum; Professional education; Soft skills; Perception.

\title{
Resumen
}

Este trabajo tiene como objetivo analizar la percepción de los estudiantes de segundo año del curso de Técnico Integrado de Automatización Industrial en el campus de IFMG Betim en relación con el uso de eduScrum como metodología de enseñanza.. EduScrum es la aplicación en educación del framework Scrum. En eduScrum, el maestro presenta a los estudiantes por qué estudiar y qué se estudiará y entregará, los estudiantes decidirán cómo aprenderán y desarrollarán la actividad propuesta. Esta metodología tiene varias etapas, tales como: trabajo en equipo, planificación de Sprint, desarrollo de Sprint, reuniones de pie, revisión de Sprint y retrospectiva de Sprint. Todos estos pasos se basan en los principios de transparencia, adaptación e inspección. Este estudio fue desarrollado a partir de una intervención 
pedagógica, y para la etapa de investigación de percepciones, se utilizó la investigación de campo. EduScrum se utilizó durante el primer trimestre de 2018 en la disciplina de fabricación industrial, CNC y sistemas hidroneumáticos. Después del final del trimestre, los 43 estudiantes respondieron un cuestionario en Google Forms. El uso de esta metodología fue muy satisfactorio, y al $90.7 \%$ de los estudiantes les gustaría que se usara en el próximo trimestre. Los principales puntos favorables para el uso de eduScrum presentados por los estudiantes fueron: el favor del aprendizaje, el desarrollo del trabajo grupal, la responsabilidad y la autonomía.

Palabras clave: eduScrum; Educación professional; Habilidades blandas; Percepción.

\section{Introdução}

A quarta revolução industrial, iniciou na primeira década do século XXI e é caracterizada pela digitalização da produção, pela internet onipresente e móvel, sensores menores e mais poderosos, inteligência artificial (Aires Moreira \& Freire, 2017) além da utilização maciça de novos sistemas de informação, da Internet das Coisas (IoT), da automação e robótica, da manufatura aditiva, da big data, da fábrica virtual, dos robôs autônomos, dos sistemas integrados e da Inteligência Artificial (IA) (CNI, 2016; Santos, Lima \& Charrua-santos, 2018; Pereira \& Simonetto, 2018; Lima \& Pinto, 2019).

Essas mudanças não ficaram limitadas ao ambiente produtivo, toda a sociedade está vivendo uma verdadeira revolução pois, segundo Schwab (2019, p. 38), "a escala e a amplitude da atual revolução tecnológica irão desdobrar-se em mudanças econômicas, sociais e culturais de proporções tão fenomenais que chega a ser quase impossível prevê-las”.

Deste modo, é preciso que a escola desenvolva nos seus alunos novas competências e habilidades para que eles possam atuar nessa nova sociedade. Diante disso, surgem duas perguntas fundamentais: Quais são essas novas competências? De que forma essas competências podem ser desenvolvidas na escola?

Vários autores destacam a importância das competências transversais ou "Soft Skills", tais como: visão sistêmica, capacidade empreendedora e gerencial, capacidade de aprender a aprender, a atitude investigativa e o saber fazer com criatividade e ousadia, comunicação oral e escrita, trabalho em equipe, responsabilidade, autonomia, negociação e gestão de conflitos. (Verticchio, 2006; Halfhill \& Nielsen, 2007; Longo, 2009; Zabala \& Arnau, 2010; Direito et

\footnotetext{
${ }^{1}$ Soft skills são competências comportamentais, relacionadas, emocionais e sociais.
} 
al., 2012; Shuayto, 2013; WEF, 2016; Aires, Kempner-moreira \& freire, 2017)

O Conselho Nacional de Educação (CNE) também sinaliza, através do artigo Terceiro das Novas Diretrizes Curriculares para a Engenharia (DCN's), que as Escolas de Engenharia devem formar um Engenheiro dentro de uma perspectiva ou visão holística, ser crítico, reflexivo, criativo, cooperativo e ético e forte formação técnica, além de atuar de forma inovadora e empreendedora (MEC/CNE, 2019). O próprio CNE indica uma possível direção para o desenvolvimento das chamadas "soft skills", o artigo sexto das DCN's da Engenharia sugere a utilização de metodologias ativas.

Entende-se por metodologias ativas como aquelas no qual a aprendizagem do aluno ocorre através do envolvimento, diálogo e motivação do aluno (Moran, 2015). Bonwell \& Eison (1991) apud Barbosa \& Moura (2013) definem aprendizagem ativa como sendo aquelas que além de ocupar os alunos, levam esse aluno a pensar sobre as coisas que está fazendo e aprendendo, ou seja, é uma educação reflexiva.

Existem várias modelos de metodologias ativas de aprendizagem, tais como, Aprendizagem Baseada em Projeto (PBL), Aprendizagem Baseada em Equipes (TBL), Ensino Híbrido, Salas de aula invertida, eduScrum entre outras.

O eduScrum foi desenvolvido pelo professor de Química do Colégio Ashram, Willy Wijnands, na cidade de Alphen aan den Rijn na Holanda. A palavra eduScrum é formada pela junção das palavras Educação e Scrum e é uma adaptação do framework Scrum para o ambiente educacional. Se baseando nos princípios do Scrum, o professor implementou, em 2011, essa metodologia nas suas turmas com alunos de faixa etária entre 12 e 18 anos (Sutherland, 2016). Para auxiliar outros Willy Wijnands fundou o eduScrum e produziu o Guia eduScrum (Delhij, Van Solingen \& Wijnands, 2017). A Figura 1 ilustra o framework eduScrum, com todos os eventos, artefatos e papeis. 
Research, Society and Development, v. 9, n. 7, e473974228, 2020

(CC BY 4.0) | ISSN 2525-3409 | DOI: http://dx.doi.org/10.33448/rsd-v9i7.4228

Figura 1: Representação esquemática do eduScrum.



Fonte: https://bit.ly/2WkipvU acessado em 23/04/2020 (modificado pelo autor).

O eduScrum possui três papeis básicos muito bem definidos: O Product Owner, o Master Scrum e a equipe de estudantes. O Professor é o Product Owner, responsável por definir os conteúdos de aprendizagem, facilitar o processo de utilização do eduScrum, auxiliar os alunos no desenvolvimento do trabalho em equipe, avaliar as entregas e fornecer feedback constante (Ibidem, 2017; Wijnands \& Stolze, 2019). Os alunos são responsáveis pelo desenvolvimento do trabalho, sendo que um aluno será o Master Scrum, que é um líder servidor, que terá como principal função garantir que o eduScrum seja utilizado durante o processo.

O presente trabalho tem como objetivo analisar a percepção dos alunos com relação à utilização do eduScrum no primeiro trimestre da disciplina Manufatura Industrial, CNC e Sistemas Hidropneumáticos do curso Técnico em Automação Industrial do IFMG campus Betim.

\section{Etapas do eduScrum}

O eduScrum possui uma série de eventos obrigatórios, os quais são apresentados na Figura 2. 
Figura 2: Etapas do eduScrum.



Fonte: (Delhij, Van Solingen \& Wijnands, 2015; Wijnands \& Stolze, 2019)

No que segue, os eventos são descritos a partir de Delhij; Van Solingen; Wijnands (2015) e Wijnands; Stolze (2019):

A primeira etapa que é realizada no início do ano é a formação das equipes. O professor forma as equipes com base nas qualidades e habilidades dos alunos. As equipes trabalham na próxima etapa, que é a Definição de pronto (DoD, Definition of Done) e a Definição de Diversão (DoF, Definition of Fun). Esses acordos se referem à qualidade das entregas e como a equipe trabalhará de forma que o desenvolvimento do trabalho ocorra de forma prazerosa. As equipes permanecerão as mesmas até o final do trabalho, já a DoD e DoF podem e devem ser alterados durante a etapa de Retrospectiva do Sprint.

As próximas etapas ocorrem durante o Sprint, Wijnands e Stolze (2019) definem o Sprint como sendo uma etapa fixa de tempo no qual o trabalho é desenvolvido. A terceira etapa é o planejamento do Sprint, nessa etapa o professor apresenta uma visão geral do trabalho, o número de aulas, as unidades didáticas do Sprint, os tipos de entregas, o modelo de avaliação, os critérios de aceitação e as datas importantes. A partir dessas informações os alunos planejam todas das tarefas que serão realizadas durante aquele Sprint. Essas tarefas são escritas em notas adesivas colocadas no Kanban, na coluna "a fazer", conforme ilustrado na Figura 3. 
Figura 3: Kanban desenvolvido pelos alunos.



Fonte: Dados da pesquisa

Depois de definir as tarefas os alunos desenvolverão o trabalho por meio das tarefas que eles definiram no evento planejamento do Sprint, enquanto a equipe estiver realizando a tarefa proposta, as notas adesivas ficam na coluna "fazendo" do Kanban, e após a conclusão da tarefa a nota adesiva é deslocada para a coluna "feito". Desta forma toda a equipe e o professor conseguem fazer a gestão do trabalho. Somente quando a tarefa cumpre os critérios estabelecidos na DoD e nos critérios de aceitação ela é deslocada para a coluna "feito". Durante o desenvolvimento do trabalho são realizados dois eventos intermediários, as reuniões de Stand-up e a construção do gráfico Run-up ou Burn down.

A reunião de Stand-up é realizada no início de todas as aulas, os alunos vão até o seu Kanban e iniciam a reunião que deve durar no máximo 5 minutos, no qual cada estudante responde às seguintes perguntas:

- $\quad$ O que eu fiz desde a última reunião de Stand-up?

- O que eu vou fazer nessa aula e até a próxima reunião de Stand-up?

- Quais os obstáculos ou impedimentos estão me atrapalhando ou atrapalhando a equipe?

As duas últimas etapas são a revisão do Sprint e a retrospectiva do Sprint, ambas são importantes para o fornecimento de feedback e inspeção do trabalho que foi desenvolvido. $\mathrm{Na}$ revisão do Sprint as equipes apresentaram o que elas fizeram e o que aprenderam no Sprint e receberão o feedback imediato do professor. A forma como acontecerá essa revisão é 
determinada pelo professor ou é definida pela equipe, podendo ser uma apresentação oral, a construção de um protótipo, uma redação, a construção de um site, um teste escrito, um TBL, entre outros. Essas são entregas intermediárias e auxiliam o professor na avaliação do processo formativo dos alunos. No final do projeto as equipes deverão entregar o resultado do projeto, seja um banner, um artigo, um site, um experimento, etc., assim como pode haver um teste final.

Ao término da revisão do Sprint as equipes farão a retrospectiva do Sprint que é uma oportunidade para a equipe de estudantes desenvolverem uma inspeção sobre si mesmos e sobre o trabalho da equipe. Os objetivos da retrospectiva do Sprint são os seguintes:

- Inspecionar como ocorreu o último Sprint, no que diz respeito a pessoas, relações, processos e ferramentas;

- Identificar as coisas que correram bem e potenciais melhorias que podem ajudar no desenvolvimento do trabalho;

- Criar um plano para implementar melhorias no modo como a equipe realiza o seu trabalho.

A retrospectiva do Sprint consiste em três partes:

- Os alunos avaliam a forma como a equipe trabalhou, identificando pontos de melhoria.

Cada aluno avalia os demais membros de sua equipe e realiza uma autoavaliação, levando em consideração a utilização das qualidades identificadas na formação da equipe e propondo melhorias.

- $\quad$ A equipe discute o que eles deveriam parar de fazer.

Os membros das equipes podem responder às seguintes perguntas para dar e receber feedback:

- O que funcionou bem?

- $\quad$ Como posso melhorar? Como eu posso ajudar na melhora dos outros?

- Como podemos nos tornar uma equipe melhor? O que devemos parar de fazer?

- Quais ações vamos implementar no próximo Sprint para trabalharmos melhor?

\section{Metodologia}

Uma pesquisa visa trazer novos saberes para a sociedade como preconiza Pereira et al. (2018). A presente pesquisa foi realizada no campus Betim do IFMG, no primeiro trimestre 
(CC BY 4.0) | ISSN 2525-3409 | DOI: http://dx.doi.org/10.33448/rsd-v9i7.4228

de 2018, com a participação do professor, dos 43 alunos da disciplina de Manufatura Industrial, CNC e Sistemas Hidropneumáticos do curso Técnico em Automação Industrial.

Quanto à tipologia da pesquisa, optou-se por desenvolver uma pesquisa de campo na qual permite ao pesquisador coletar e analisar dados empíricos no próprio local onde os fenômenos ocorrem (Marconi \& Lakatos, 2004). Dentre as possibilidades dessa investigação escolheu-se a modalidade de intervenção pedagógica no qual os participantes e o pesquisador atuam durante a investigação, ou seja, ambos são aprendizes nesse processo de mudança na prática de ensino (Damiani et. al., 2013).

$\mathrm{Na}$ primeira aula foi apresentado a metodologia que seria utilizada, focando principalmente nos motivos pelo qual o trabalho seria desenvolvido dessa forma e foi contextualizado os objetos de estudo propostos para o trimestre.

Na segunda aula foi realizada uma dinâmica para a formação das equipes. Nessa, os alunos realizaram uma autoavaliação das suas características e competências, e os grupos foram formados de modo que cada um fosse formado por uma equipe com multicompetências e com alunos que possuíam características diferentes.

Nessa aula foi entregue aos alunos o backlog da disciplina, com todos os objetivos de aprendizagem, conforme mostra o Quadro 1. Esse backlog indica o conteúdo que deve ser trabalhado durante o Sprint, ou seja, foi definido o que deve ser aprendido, os alunos definiram como vão desenvolver e aprender o trabalho. É importante destacar que o professor atua como mentor dos grupos durante todo o processo, verificando o aprendizado, elucidando as dúvidas que surgem e fornecendo feedback tanto do ponto de vista do conteúdo, quanto dos procedimentos e atitudes dos alunos durante o trabalho. 
Figura 4: Banner apresentado pelos alunos no final do Trimestre.

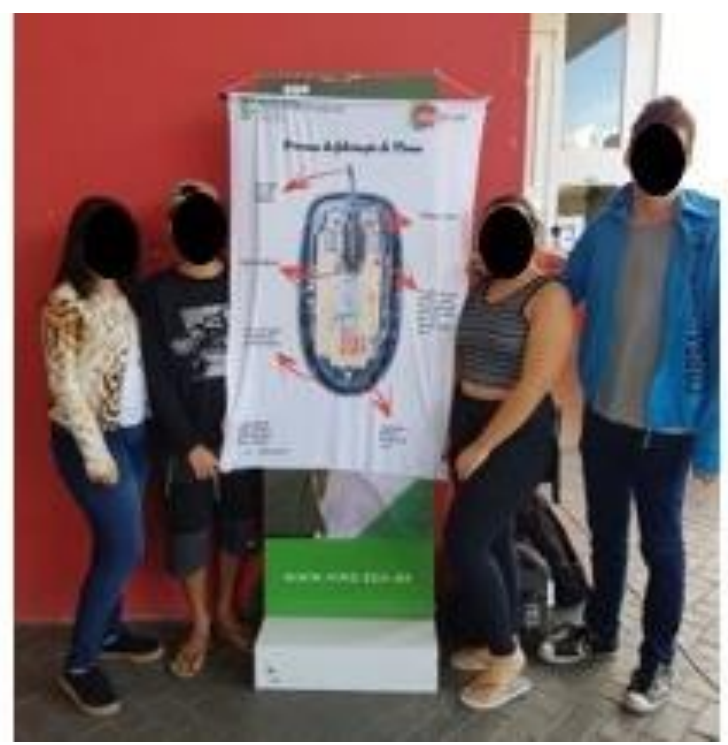

Fonte: Dados da pesquisa.

Quadro 1 - Backlog utilizado durante a disciplina.

\begin{tabular}{|cl|}
\hline Prioridade & \multicolumn{1}{c|}{ Backlog } \\
\hline 1 & $\begin{array}{l}\text { Classificação dos principais processos de fabricação de materiais mecânicos, polímeros e } \\
\text { cerâmicos, com relação à energia envolvida e temperatura do processo. Tipo de apresentação: } \\
\text { Livre }\end{array}$ \\
\hline 2 & $\begin{array}{l}\text { Descrição dos processos de fabricação de conformação mecânica (mínimo: laminação, } \\
\text { trefilação, extrusão, forjamento e estampagem). Tipo de apresentação: Construção de um } \\
\text { Protótipo e filme (mínimo } 3 \text { min e máximo } 5 \text { min) }\end{array}$ \\
\hline 3 & $\begin{array}{l}\text { Descrição dos processos de fabricação de fundição (mínimo: areia verde, sob pressão, cera } \\
\text { perdida e shell molding). Tipo de apresentação: Livre }\end{array}$ \\
\hline 4 & $\begin{array}{l}\text { Descrição dos processos de fabricação de usinagem (mínimo: torneamento, fresamento e } \\
\text { retificação). Tipo de apresentação: Livre }\end{array}$ \\
\hline 5 & $\begin{array}{l}\text { Descrição dos processos de fabricação de soldagem (Mínimo: Eletrodo revestido, MIG/MAG } \\
\text { e TIG). Tipo de apresentação: Relatório escrito }\end{array}$ \\
\hline 6 & $\begin{array}{l}\text { Descrição dos processos de fabricação utilizados nos polímeros (Mínimo: sopro e injeção): } \\
\text { Tipo de apresentação: Power Point }\end{array}$ \\
\hline 7 & Descrição dos processos de fabricação utilizados nos cerâmicos. Tipo de apresentação: Livre \\
\hline
\end{tabular}

\section{Fonte: Autores.}

Durante as outras aulas do trimestre, que constavam de 50 minutos, a sequência de trabalho foi o seguinte: 1 aula para o planejamento do Sprint, 2 aulas para que os alunos 
desenvolvessem o trabalho, 1 aula para a apresentação do trabalho (Revisão do Sprint) e 1 aula para autoavaliação da equipe (Retrospectiva do Sprint).

No final do trimestre os alunos apresentaram um Banner, no qual todos os processos de fabricação de um produto escolhido no início do trimestre foram descritos, Figura 4.

Para avaliar a metodologia foi aplicado um questionário na plataforma Google Forms ${ }^{2}$ para todos os 43 alunos da turma, sendo que todos o responderam. No Quadro 2 estão as perguntas relacionadas à percepção dos alunos com relação ao eduScrum.

Após a coleta das respostas dos estudantes, esses foram analisados de uma maneira interpretativo-descritiva, compondo um texto de análise que traz dados numéricos e as respostas de alguns participantes para embasar as conclusões tiradas a partir mesmos. Para tal, com intuito de garantir os princípios da ética na pesquisa, os alunos foram identificados por A1, A2, ... A43, não sendo identificados no processo.

Quadro 2: Perguntas relacionadas à percepção do eduScrum.

\begin{tabular}{|c|c|}
\hline $\begin{array}{l}\text { Número da } \\
\text { Pergunta/Afirmação }\end{array}$ & Pergunta \\
\hline 1 & Você gostaria que fosse utilizado o eduScrum na próxima etapa? Justifique sua resposta \\
\hline 2 & $\begin{array}{l}\text { O grupo melhorou durante o desenvolvimento do trabalho. (realizando as tarefas mais } \\
\text { rápido e de forma mais organizada) }\end{array}$ \\
\hline 3 & $\begin{array}{l}\text { O trabalho desenvolvido pelo eduScrum foi igual a todos os trabalhos em grupo que eu } \\
\text { já participei. }\end{array}$ \\
\hline 4 & Eu aprendi pouco durante o desenvolvimento desse trabalho. \\
\hline 5 & $\begin{array}{l}\text { Escreva um texto argumentando a favor ou contra a continuação da utilização do } \\
\text { eduScrum na disciplina de Manufatura Industrial, CNC e Hidropneumática. Nesse texto } \\
\text { você pode propor melhorias, apontar falhas e dar sua opinião livremente. }\end{array}$ \\
\hline
\end{tabular}

Fonte: Autores.

\section{Resultados e discussão}

Através dos resultados obtidos verifica-se que a metodologia utilizada teve uma elevada aprovação por parte dos alunos, visto que 90,7\% dos mesmos responderam que gostariam que o eduScrum fosse utilizado no próximo trimestre, conforme mostra o Gráfico 1.

${ }^{2}$ O Google Forms é um aplicativo de administração de pesquisas incluído no pacote do escritório do Google Drive. Disponível em: <https://www.google.com/forms/about/> 
Research, Society and Development, v. 9, n. 7, e473974228, 2020

(CC BY 4.0) | ISSN 2525-3409 | DOI: http://dx.doi.org/10.33448/rsd-v9i7.4228

Gráfico 1: Resposta dos alunos para a Pergunta 1: Você gostaria que fosse utilizado o eduScrum na próxima etapa?

Você gostaria que fosse utilizado o eduScrum na próxima etapa? 43 respostas

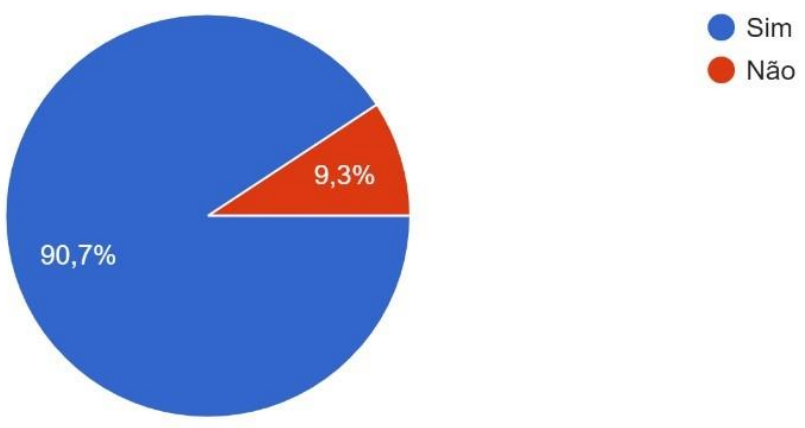

Fonte: Dados da pesquisa

Ao analisar as justificativas fornecidas pelos alunos, pode-se estratificar as respostas dos alunos destacando os seguintes pontos positivos da utilização da metodologia:

\section{A) Melhora dos resultados acadêmicos e aprendizado:}

A4: "Devido aos bons resultados acadêmicos que o EduScrum proporcionou."

A12: "Porque no meu ponto o Scrum foi um método que me fez estudar realmente, para aprender a matéria, uma vez que se fosse o método tradicional eu estudaria a matéria somente quando fosse ter prova e consequentemente não iria ter bons resultados e esqueceria a matéria"

A15: "É um método que funciona, todos do grupo conseguem aprender o que é pedido."

A31: "É uma forma muito interessante de aprendizado, na minha opinião é um método bem melhor do que uma aula normal; aprendemos com maior facilidade"

O aprendizado também foi autoavaliado pelos alunos através da Afirmativa 4: $E u$ aprendi pouco durante o desenvolvimento desse trabalho. Dos 43 alunos que responderam ao questionário $86,1 \%$ discordam completamente ou discordam da afirmativa, ou seja, houve uma grande percepção dos alunos de que houve aprendizado durante o desenvolvimento da disciplina, conforme ilustra o Gráfico 2. 
Gráfico 2: Respostas dos alunos à afirmativa 4: Eu aprendi pouco durante o desenvolvimento desse trabalho.

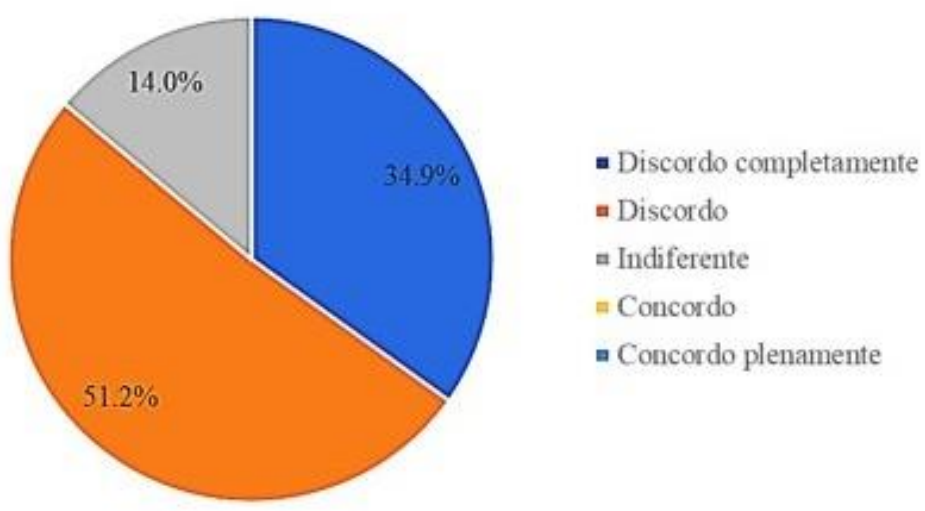

Fonte: Dados da pesquisa

\section{B) Melhoria no trabalho em equipe/grupo:}

Com relação ao trabalho em equipe, os Alunos A24 e A13 destacam nas suas justificativas que o aprendizado foi facilitado devido ao trabalho em grupo, corroborando com as ideias de Damiani (2008) que destaca as vantagens das atividades em equipe ou compartilhadas, afirmando que tanto a colaboração quanto a comunicação são aspectos importantes para que uma pessoa se torne um aprendiz bem-sucedido.

A24: "O método me ajudou muito a aprender por causa das reuniões em grupo, onde pesquisavamos e solucionavamos duvidas em equipe, alem do fato que poderemos melhorar e aplicar o método em algo bom no futuro"

A13: "O processo de aprendizagem com o EduScrum é muito interessante pelo trabalho em grupo, o grupo aprende junto, se avalia junto, auxilia muito no trabalho em grupo, tendo isso como pontos positivos (...)"

A17: "Pois foi um método em que nos ensinou a trabalhar em grupo. Com ele pude perceber que se eu me empenhar e trabalhar em equipe sou capaz de aprender, mesmo que o professor nao de aula e sim auxilie"

A afirmação 2: O grupo melhorou durante o desenvolvimento do trabalho. (realizando as tarefas mais rápido e de forma mais organizada) e a afirmação 3: $O$ trabalho desenvolvido pelo eduScrum foi igual a todos os trabalhos em grupo que eu já participei. foram utilizadas 
para avaliar a percepção dos alunos com relação ao trabalho em equipe desenvolvido durante o eduScrum. O Gráfico 3 mostra que $95,4 \%$ dos alunos consideram que os seus grupos melhoraram durante o trabalho e $83,8 \%$ dos alunos avaliaram o trabalho desenvolvido como sendo diferente dos trabalhos que eles já participaram.

Gráfico 3: Respostas dos alunos para a afirmativa 2 (esq.) e para a afirmativa 3 (dir.)


- Discordo completamente

a Discordo

Indiferente

= Concordo

- Concordo plenamente

Fonte: Dados da pesquisa

\section{C) Desenvolvimento da Autonomia e Responsabilidade:}

Vários alunos destacaram o desenvolvimento da autonomia e da responsabilidade durante a utilização do eduScrum, isso é uma das principais características da metodologia, pois os alunos decidem e planejam como vão trabalhar durante o Sprint e também são responsáveis pela qualidade da entrega.

A6: "Eu acho que por mais que no início faltou um pouco de compromisso dos alunos porem aos poucos todos foram amadurecendo e o eduscrum acabou se tornando um ótimo meio de aprendizado onde a grande maioria pode se dedicar e aprender bastante sobre todos os assuntos"

A7: "O eduScrum é um método que dar maior liberdade aos alunos, e dessa maneira os mesmos podem criar maior responsabilidade. Além disso as notas obtidas de maneira geral no primeiro trimestre foram boas, logo pode-se dizer que foi um método diferente e de certa maneira um pouco mais complicado, porém que deu certo" 
Research, Society and Development, v. 9, n. 7, e473974228, 2020

(CC BY 4.0) | ISSN 2525-3409 | DOI: http://dx.doi.org/10.33448/rsd-v9i7.4228

A43: "Eu gostaria que esse método se repetisse na próxima etapa pois foi divertido, a gente aprendeu a ter autonomia, era uma matéria diferente de tudo que a gente tem no IFMG com métodos diferente e isso cria uma animação para participar"

Os alunos também apontaram pontos negativos ou dificuldades apresentadas durante o trimestre, a que mais se destaca é a falta de tempo. Considerando que o trabalho foi desenvolvido em uma turma do curso Técnico Integrado, ou seja, os alunos fazem o Ensino Médio integrado ao Ensino Tecnológico, essa dificuldade já era esperada e precisa ser levada em consideração durante a aplicação de metodologias ativas.

\section{A3: "Pois estamos tendo cada vez mais atividade e o eduScrum demanda tempo"}

A19: "Acredito no EduScrum e que seja um método eficaz, mas não no contexto de uma escola de ensino médio técnico integral, uma vez que possuímos várias matérias e todas exigem de nós uma certa dedicação, já que pelo menos eu almejo sair do IFMG uma técnica de qualidade, que saiba pelo menos o básico, mas de uma forma para atuação na área"

A20: “(...) No entanto, ele possui alguns pontos negativos, como está sendo feito em uma escola técnica o mesmo consome um tempo maior e dificulta o rendimento em outras matérias. Conclui que seria possível o uso do eduScrum na próxima etapa, mas acho que seria melhor se houvessem melhorias e adaptação do método"

A23: "O eduScrum é um bom modo de aprendizado em que um ajuda o outro. Apesar de estar sendo difícil fazer todos os backlogs, pelo tempo que é pouco se comparado com as outras matérias"

Já na pergunta 6 foi solicitado aos alunos que escrevessem um texto argumentando a favor ou contra a utilização do eduScrum, ao fazer uma nuvem de palavras, Figura 5, a partir das respostas verifica-se que as palavras mais citadas foram "eduScrum", "Grupo", "Aula”, "Melhor”, "Trabalho", "Matéria”, "Tempo".

Conforme indicado no mapa mental os alunos destacaram o trabalho em grupo como sendo uma das características principais da metodologia, além disso os alunos destacaram que o professor deveria ministrar algumas aulas durante o Sprint e acompanhar alguns grupos mais de perto. No modo geral os alunos aprovaram a utilização da metodologia, pois aprenderam a matéria de forma ativa e prazerosa. 
Figura 5: Nuvem de palavras construída a partir das respostas dos alunos para a Pergunta 6.

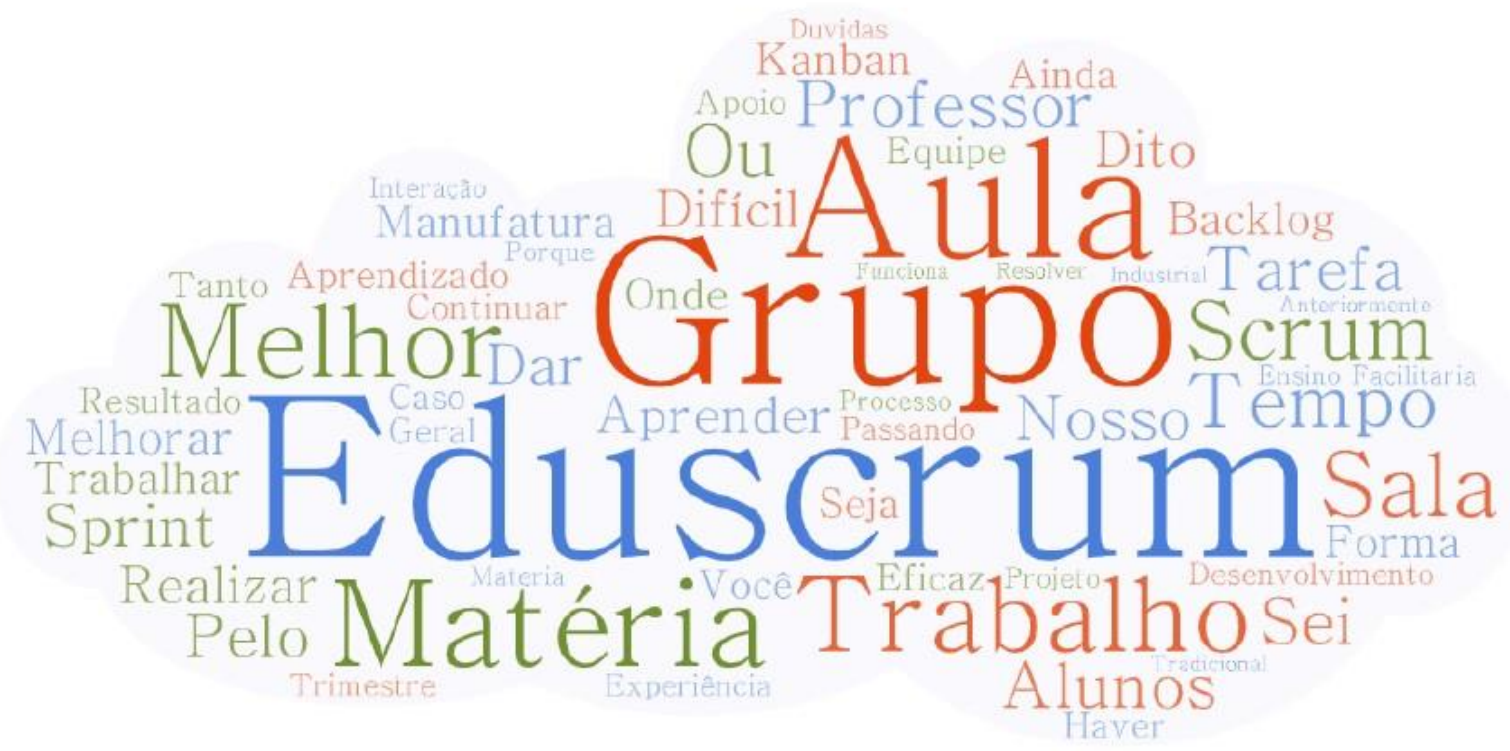

Fonte: Dados da pesquisa

\section{Conclusão}

A sociedade está em constante transformação e cada vez mais as pessoas precisaram desenvolver novas competências e habilidades, principalmente as relacionadas à criatividade, trabalho em equipe, responsabilidade e autonomia.

Os resultados obtidos nessa pesquisa indicam que a utilização do eduScrum, como metodologia de ensino, possibilita o desenvolvimento dessas competências e habilidades nos alunos. Outro ponto favorável à utilização dessa metodologia de ensino foi o alto índice de aprovação e satisfação apresentada pelos alunos, 90,7\% gostariam que o eduScrum fosse utilizado no próximo trimestre, esse é um indicador relevante, pois os fatores afetivos e motivacionais são importantes para o desenvolvimento cognitivo e aprendizagem.

Nas próximas pesquisas é recomendado que o eduScrum seja utilizado em disciplinas que possuam características mais práticas de modo a avaliar a sua aplicabilidade nesse tipo de disciplina, outra pesquisa que pode validar a utilização desse framework é por meio da utilização da metodologia Aprendizagem Baseada em Projetos (PBL, Problem based learning) com e sem o eduScrum, verificando assim o impacto de sua utilização no processo de ensino e aprendizagem. 


\section{Referências}

Aires, RWDA, Kempner-Moreira, FK \& Freire, PDS. (2017, September). Indústria 4.0: competências requeridas aos profissionais da quarta revolução industrial. In congresso internacional de conhecimento e inovação (CIKI) (Vol. 7).

Barbosa, EF \& de Moura, DG. (2013). Metodologias ativas de aprendizagem na educação profissional e tecnológica. Boletim Técnico do Senac, 39(2), 48-67.

CNI, CDI. (2016). Indústria 4.0: novo Desafio para a indústria Brasileira. Indicadores CNI, $17,13$.

Damiani, MF. (2008). Entendendo o trabalho colaborativo em educação e revelando seus benefícios. Educar em revista, (31), 213-230.

Damiani, MF, Rochefort, RS, Castro, RF, Dariz, MR \& Pinheiro, SS. (2013). Discutindo pesquisas do tipo intervenção pedagógica. Cadernos de educação, (45), 57-67.

Delhij, A, Van Solingen, R \& Wijnands, W. (2017). O guia eduScrum: as regras do jogo. 2016. Retrieved October, 31.

Direito, I, Pereira, A \& de Oliveira Duarte, AM. (2012). Engineering undergraduates' perceptions of soft skills: Relations with self-efficacy and learning styles. Procedia-Social and Behavioral Sciences, 55, 843-851.

Halfhill, TR \& Nielsen, TM. (2007). Quantifying the "softer side" of management education: An example using teamwork competencies. Journal of Management Education, 31(1), 64-80.

Lima, AG \& Pinto, GS. (2019). INDÚSTRIA 4.0. Revista Interface Tecnológica, 16(2), 299311.

Longo, WPE. (2009). O Programa de Desenvolvimento das Engenharias. Revista Brasileira De Inovação, 3(2), 417-47. 
Marconi, MDA \& Lakatos, EM. (2004). Metodologia científica (Vol. 4). São Paulo: Atlas.

Ministério da Educação/Conselho Nacional de Educação (2019). Resolução CNE/CES 02/2019, aprovada em 24 de abril de 2019. Institui as Diretrizes Curriculares Nacionais do Curso de Graduação em Engenharia. Brasília.

Morán, J. (2015). Mudando a educação com metodologias ativas. Coleção mídias contemporâneas. Convergências midiáticas, educação e cidadania: aproximações jovens, 2(1), 15-33.

Pereira, AS, Shitsuka, DM, Parreira, FJ \& Shitsuka, R. (2018). Metodologia da pesquisa científica. [e-book]. Santa Maria. Ed. UAB/NTE/UFSM. Disponível em: https://repositorio.ufsm.br/bitstream/handle/1/15824/Lic_Computacao_MetodologiaPesquisa-Cientifica.pdf?sequence $=1$.

Pereira, A \& de Simonetto, OE. (2018). Indústria 4.0: conceitos e perspectivas para o Brasil. Revista da Universidade Vale do Rio Verde, 16(1).

Santos, BP, Alberto, A Lima, TDFM \& Charrua-Santos, FMB. (2018). Indústria 4.0: desafios e oportunidades. Revista Produção e Desenvolvimento, 4(1), 111-24.

Schwab, K. (2019). A quarta revolução industrial. Edipro.

Shuayto, N. (2013). Management skills desired by business school deans and employers: An empirical investigation. Business Education \& Accreditation, 5(2), 93-105.

Sutherland, J. (2016). Scrum: a arte de fazer o dobro do trabalho na metade do tempo. Leya.

Verticchio, NDM. (2006). Análise comparativa das habilidades e competências necessárias para o engenheiro na visão da indústria, dos discentes e dos docentes. Belo Horizonte, Brasil.

Wijnands, W \& Stolze, A. (2019). Transforming Education with eduScrum. In Agile and Lean Concepts for Teaching and Learning (pp. 95-114). Springer, Singapore. 
World Economic Forum. (2016, January). The future of jobs: Employment, skills and workforce strategy for the fourth industrial revolution. In Global Challenge Insight Report, World Economic Forum, Geneva.

Zabala, A \& Arnau, L. Como aprender e ensinar competências. Tradução de Carlos Henrique Lucas Lima. Porto Alegre: Artmed, 2010. Práxis Educativa, 6(1), 133-134.

\section{Porcentagem de contribuição de cada autor no manuscrito}

Norimar de Melo Verticchio - 60\%

Gabriel de Oliveira Soares - 40\% 